\title{
Burden and Quality of Life Among Female and Male Patients with Heart Failure in Europe: A Real-World Cross-Sectional Study
}

\author{
Ana Filipa Fonseca' \\ Raquel Lahoz $\mathbb{D}^{\prime}$ \\ Clare Proudfoot ${ }^{\prime}$ \\ Stefano Corda' \\ Emil Loefroth' \\ James Jackson (iD) ${ }^{2}$ \\ Sarah Cotton (1D) ${ }^{2}$ \\ Rachel Studer (D)
}

'Novartis Pharma AG, Basel, Switzerland;

${ }^{2}$ Adelphi Real World, Bollington, UK
Purpose: To characterize symptoms, clinical burden, and health-related quality of life (HRQoL) among women and men with heart failure (HF) with a left ventricular ejection fraction (LVEF) of $\leq 60 \%$ in Europe.

Patients and Methods: A real-world cross-sectional study was conducted in France, Germany, Italy, Spain, and United Kingdom from June to November 2019. Patient record forms were completed by 257 cardiologists and 158 general practitioners for consecutive patients with HF. The same patients were invited to complete a questionnaire comprising patient-reported outcomes: the Minnesota Living with Heart Failure Questionnaire (MLHFQ), five-level five-dimension EuroQol questionnaire (EQ-5D-5L), Visual Analogue Scale (VAS), and Work Productivity and Activity Impairment questionnaire.

Results: The mean age of 804 patients (men, $\mathrm{n}=517$; women, $\mathrm{n}=287$ ) was 68.6 years (men, 67.8 years; women, 70.2 years; $p=0.0022$ ). The mean LVEF was $44.7 \%$ (men, $43.6 \%$; women, 46.8\%; $<<0.0001$ ). Patients reported dyspnoea when active (overall, 55.7\%; men, $56.0 \%$; women, $55.3 \%$ ), fatigue/weakness/faintness (34.5\%; men, $32.9 \%$; women, $37.2 \%$ ), and oedema (20.3\%; men, $18.7 \%$; women, $23.1 \%$ ) as the most troublesome HF symptoms. Overall, $54.1 \%$ of patients reported low mood/depression (men, 50.8\%; women, $60.1 \%$ ). The overall MLHFQ mean score was higher (ie, poorer HRQoL) among women vs men (37.9 vs 34.6; $\mathrm{p}=0.0481$ ). MLHFQ was consistently higher (ie, poorer HRQoL) for women vs men across the physical (18.6 vs 16.6; $\mathrm{p}=0.0041)$ and emotional (9.4 vs 7.9; $\mathrm{p}=0.0021)$ scoring domains. Mean EQ-5D utility ( 0.69 vs $0.75 ; \mathrm{p}=0.0046)$ and VAS scores (55.4 vs 61.3 ; $\mathrm{p}<0.0001)$ were lower among women compared with men. Overall, $23.4 \%$ of patients were hospitalized owing to HF in the previous year (men, 22.7\%; women, 24.6\%). Patients reported $43.2 \%$ activity impairment due to HF (men, $41.6 \%$; women, $46.4 \%$; $\mathrm{p}=0.01$ ).

Conclusion: HF causes a substantial burden on patients, with a greater burden among women vs men. This gender-related difference is consistent with other HF studies, warranting further research to understand the underlying reasons.

Keywords: burden, gender, heart failure, health-related quality of life, real-world, work productivity

\section{Introduction}

Heart failure (HF) is a chronic disease characterized by the reduced ability of the heart to pump and/or fill up with blood. ${ }^{1} \mathrm{HF}$ is a serious public health problem affecting an estimated 40 million people worldwide ${ }^{2}$ and more than 15 million people in Europe. ${ }^{3}$ Given that the world's ageing population is growing and that HF is more prevalent with age, HF prevalence has also been estimated to increase
Real World Evidence Group, CardioRenal-Metabolic Franchise, Novartis Pharma AG, Novartis Campus, Basel, $\mathrm{CH}-4002$, Switzerland

Tel: +4I (0) 793489979

Email ana_filipa.fonseca@novartis.com 
further, with a 40\% projected rise between 2015 and $2035 .^{4}$ Thus, HF is likely to become one of the world's most prevalent chronic conditions.

$\mathrm{HF}$ is a progressive and symptomatic disease and has an adverse impact on patients' lives. Patients with HF experience various physical and emotional symptoms, including shortness of breath (dyspnoea), fatigue, swelling of the ankles or abdomen, sleep difficulties, depression, and chest pain. ${ }^{1,5} \mathrm{HF}$ is associated with high morbidity and poor prognosis, to an extent similar to cancer, ${ }^{6}$ and substantially impacts patients' health-related quality of life (HRQoL), with nearly $75 \%$ of patients reporting difficulties in performing activities of daily living. ${ }^{7}$ The devastating nature of $\mathrm{HF}$ can make patients dependent on caregivers and lead to social isolation, anxiety, and depression. ${ }^{8}$ Patients with HF have a markedly reduced HRQoL compared with those with other chronic diseases and the healthy population. ${ }^{9,10}$ A poorer HRQoL in HF patients is associated with increased hospitalizations and death, with approximately 3 million hospitalizations and numerous deaths reported in Europe annually. ${ }^{3}$ The financial burden of HF is substantial, and contributes to $1-2 \%$ of the total healthcare expenditure in Europe. ${ }^{8,11}$ Some evidence also suggests that the negative impact of HF on the HRQoL of women is greater vs men, with emotional well-being and mental health being more impaired in women vs men. ${ }^{9,12-14}$

The disease burden in patients with HF with reduced ejection fraction (HFrEF; left ventricular ejection fraction [LVEF] $<40 \%$ ) has been studied extensively, and some therapies have shown benefits in the treatment of HFrEF. ${ }^{1}$ A few randomized controlled trials have shown evidence of effectiveness in patients with a higher LVEF, including CHARM (LVEF $>40 \%)^{15}$ and PARAGON-HF (LVEF $\geq 45 \%) .{ }^{16}$ Data from the PARAGON-HF trial showed an interaction between LVEF and treatment effect, with patients with an LVEF below the trial median of 57\% deriving a greater benefit than those with an LVEF above this level. Such data have provoked interest in considering HF patients with an LVEF below the normal level (typically considered as an LVEF of approximately $55 \%-60 \%$, with sex-specific differences) as a population who may benefit from the currently available pharmacotherapies, such as sacubitril/valsartan. ${ }^{17}$

In this study, we selected patients with HF with a subnormal or reduced LVEF, applying a threshold of LVEF $\leq 60 \%$. The European Society of Cardiology (ESC) defines patients based on LVEF as HFrEF (LVEF $<40 \%$ ), HF with mid-range EF (LVEF 40-49\%) and HF with preserved EF $(\mathrm{LVEF} \geq 50 \%),{ }^{1}$ however, HF is a heterogeneous disease with a spectrum of phenotypes with overlapping and distinct characteristics. ${ }^{18}$ The understanding of HF and classification of $\mathrm{HF}$ phenotypes continues to evolve. ${ }^{17,18}$ Recently, the Food and Drug Administration of the United States approved an expanded indication for sacubitril/valsartan in chronic $\mathrm{HF},{ }^{19}$ recognizing the benefit particularly in patients with a sub-normal LVEF, as shown in the PARAGON-HF ${ }^{16}$ and PARADIGM-HF ${ }^{20}$ studies. This study was aimed at better understanding a population with an LVEF below normal, defined here as LVEF $\leq 60 \%$, which has the greatest potential to benefit from sacubitril/valsartan. There is a lack of evidence on the burden in the overall population of HF patients with a sub-normal LVEF, and information by sex is scarce. For these reasons, we aimed to assess the symptoms, clinical burden, and HRQoL among patients with HF with an LVEF of $\leq 60 \%$ from both the patient and physician perspective in a realworld setting of five countries from Europe. We also aimed to investigate whether differences existed in the symptoms, clinical burden, and HRQoL between men and women with HF. The findings from this study will also help to inform health policy makers on the current burden of HF prevailing in Europe.

\section{Materials and Methods Study Design}

The Adelphi Disease Specific Programme (DSP) ${ }^{\mathrm{TM}}$ is a large multinational survey conducted in clinical practice that describes patient characteristics, current disease management, impact of the disease burden, and associated treatment effects. The DSPTM methodology has been published previously. ${ }^{21-23}$ This was a cross-sectional survey of patients with HF conducted in a real-world setting in France, Germany, Italy, Spain, and the United Kingdom from June to November 2019.

The HF DSPTM incorporates four questionnaires: a physician survey, a patient record form, a patient selfcompletion questionnaire, and a caregiver self-completion questionnaire. Physicians were included if they were cardiologists or general practitioners (GPs), were actively involved in managing HF patients (ie, monthly treatment of $\geq 16$ patients with HF for cardiologists and eight patients with HF for GPs), and consented to participate. All components completed by the physician were online. Physicians completed patient record forms for eight 
consecutive HF patients who consulted them, using data from medical records. Patient self-completion questionnaires were voluntarily completed by the patients whose information was recorded in the patient record forms.

The study was conducted in accordance with the ethical principles as per the Declaration of Helsinki. Since this study involved the participation of human subjects, the protocol was submitted to the Western International Review Board (study protocol number 8649). However, a waiver was provided by the Board because the study aimed to improve understanding rather than testing hypotheses and the ethical approval was not considered necessary. Informed consents were obtained from physicians, patients, and caregivers before the start of study.

\section{Patient Selection}

Consecutive patients from the same physicians were included if they were aged $\geq 18$ years, had a confirmed diagnosis of HF, and consented to voluntarily fill the patient self-completion questionnaire. Patients who were involved in any clinical trial were not included.

\section{Study Measures}

Physician surveys captured data on type of practice, including information on the aetiology and management of $\mathrm{HF}$ and awareness/adherence to local/national HF guidelines. Physician-completed patient record forms included data on patient demographics, symptoms of HF, disease severity, treatment patterns, satisfaction with care, comorbidities, and healthcare resource use. Information collected in the patient self-completion questionnaire comprised demographics, lifestyle, disease awareness, common symptoms of HF and how troublesome they were, disruption in patients' everyday life, caregiving assistance required, impact of HF on work productivity and HRQoL, and economic burden. Disruption in patients' everyday life was measured on a scale of 1 ("no disruption at all") to 10 ("severe disruption").

HRQoL was measured using the Minnesota Living with Heart Failure Questionnaire (MLHFQ) and the fivelevel five-dimension EuroQol questionnaire (EQ-5D-5L). MLHFQ is an HF-specific questionnaire, consisting of 21 items rated on a six-point Likert scale, and provides an overview of the degree of impact on a patient's HRQoL due to HF (scores of 0 [none] to 5 [very much]). The MLHFQ yields a total score (range: 0 105, from best to worst HRQoL), and scores for two dimensions: physical (range: 0-40) and emotional (range: $0-25)^{24}$ EQ-5D is a generic instrument consisting of a five-question descriptive system (EQ-5D index) and a 100-point visual analogue scale (EQ-5D VAS). ${ }^{25,26}$ The EQ-5D descriptive system measures five dimensions of the health status, ie, mobility, self-care, usual activities, pain/discomfort, and anxiety/depression, using five levels per dimension (no, slight, moderate, severe, and extreme problems). ${ }^{27}$ The validity and reliability of the EQ-5D as an outcome measure in HF has been published. $^{28}$ In line with the National Institute for Health and Care Excellence (NICE) guidelines, the EQ5D-5L scores were cross-walked to the EQ-5D-3L scores. $^{29}$

Clinical burden was assessed in terms of patients' visits to a doctor or hospitalization in the last 12 months. The impact on work productivity was measured using the Work Productivity and Activity Impairment (WPAI) survey comprising six questions, with the first one being on employment status and the remaining on the assessment of work time missed and work and activity impairment owing to HF in the last 7 days. $^{30}$

\section{Data Analysis}

After the survey, anonymized, aggregated data were received and analyzed. Descriptive statistics were reported as frequency and/or percentages for categorical variables and as mean, standard deviation (SD), median, range, and first and third quartiles for continuous variables. Data for missing values were not imputed. All data were analyzed using $\mathrm{UNICOM}^{\circledR}$ Intelligence Reporter version 7.5, a database creation software (IBM ${ }^{\circledR}$ SPSS $^{\circledR}$ Statistics version 25). Statistical tests to demonstrate the difference between both genders included the Fisher's Exact test, Mann-Whitney test, and Pearson's chi-square test. The value of $p<0.05$ was considered significant.

\section{Results}

In total, 415 physicians participated in this study (257 cardiologists and $158 \mathrm{GPs})$. They completed patient record forms for 3316 patients with HF (2479 of these have LVEF $\leq 60 \%)$. Of the 3316 patients, 2019 (61\%) were attended by cardiologists and 1297 (39\%) were attended by GPs. Approximately one-third $(\mathrm{n}=1062 ; 32.0 \%)$ of the patients for whom a patient record form was completed by a physician also completed a patient self-completion questionnaire. Of these 1062 patients, 804 had HF with an LVEF of $60 \%$ or lower. 


\section{Physician Characteristics}

Of the 257 cardiologists, $45 \%$ were specialized in noninvasive/non-interventional cardiology, $27 \%$ in HF cardiology, and $17 \%$ in invasive/interventional cardiology. Cardiologists attended most of their patients in a public hospital (59\% of patients), followed by a public office (24\%), and a private hospital/public office (17\%). Nearly three-quarters of the GPs (72\%) had a special interest in HF. GPs largely saw their patients in a public $(72 \%$ of patients) vs private office $(23 \%)$.

\section{Patient Demographics and Baseline Clinical Characteristics}

Of the 804 patients, $64.3 \%(n=517)$ were men. The mean age of patients was 68.6 years; women being significantly older than men ( 70.2 vs 67.8 years; $p<0.0022$ ). The mean body mass index for all patients was $27.8 \mathrm{~kg} / \mathrm{m}^{2}$ and was higher in men vs women (27.9 vs $27.6 \mathrm{~kg} / \mathrm{m}^{2}$; $\mathrm{p}=0.025$ ). Overall, $11.6 \%$ of patients were current smokers and $22.4 \%$ were current consumers of alcohol. Both habits were significantly higher among men compared with women $(\mathrm{p}<0.0001)$ (Table 1). More women were living alone vs men (32.1\% vs $16.4 \%)$. Most (83.0\%) patients were in the New York Heart Association (NYHA) function classes II and III, with no remarkable difference across both genders. The mean (SD) LVEF for all patients was $44.7 \%(9.8 \%)$, with a significantly greater LVEF in women vs men ( $46.8 \%$ vs $43.6 \%$; $\mathrm{p}<0.001)$. Hypertension (55.1\%), hyperlipidaemia (36.2\%), and atrial fibrillation $(20.0 \%)$ were the most common comorbidities in both genders (Table 1).

\section{Common Symptoms of HF}

The most common current symptoms experienced by HF patients included shortness of breath when active (73.0\%), fatigue/weakness/faintness (58.0\%), oedema (42.0\%), and nocturia (25.0\%). Fatigue/weakness, oedema, and palpitations were higher among women compared with men (Figure 1). Shortness of breath when active $(56.0 \%)$, fatigue/weakness (35.0\%), and oedema (20.0\%) were reported as the most troublesome symptoms by patients; fatigue/weakness/faintness and oedema were more frequently reported as the most troublesome symptoms by women vs men (Figure 1).

\section{Disruption in Patient's Everyday Life Due to HF}

On a scale from 1 (no disruption) to 10 (severe disruption), patients $(\mathrm{n}=757)$ gave a mean (SD) score of 4.9 (2.4) to indicate the level of disruption in their everyday life. Women and men reported similar levels of disruption in their lives due to HF, with no significant difference in the mean (SD) scores across both genders (men [n=487]: 4.8 [2.3]; women [ $n=270$ ]: 5.0 [2.4]; $p=0.4987)$. Overall $64 \%$ of patients required support from their family or professional caregivers to perform everyday activities (men: $62 \%$; women: $67 \%$ ).

More than half of the patients $(54.1 \%)$ reported that they experienced low mood/depression due to HF either sometimes, often, or always, with a higher proportion of women experiencing low mood/depression vs men (60.1\% vs $50.8 \%$ ) (Figure $2 \mathrm{~A}$ ). A significantly higher proportion of women compared with men reported anxiety due to HF ( $\mathrm{p}=0.0004$ ), with $62.4 \%$ of women experiencing anxiety due to HF either sometimes, often, or always compared with $52.2 \%$ of men (Figure $2 \mathrm{~B}$ ).

\section{Impact of HF on Patients' HRQoL MLHFQ Scores}

The overall MLHFQ mean score was 35.8, with a significantly higher score (indicative of poorer HRQoL) observed in women vs men (37.9 vs 34.6; $\mathrm{p}=0.0481$ ) (Table 2). The HRQoL was consistently poorer for women across the physical and emotional scoring domains as well ( $\mathrm{p}=0.0041$ and 0.0021 , respectively).

\section{EQ-5D Scores}

We observed significantly lower mean EQ-5D index (0.69 vs $0.75 ; \mathrm{p}=0.0046$ ) and EQ-5D VAS scores (55.4 vs 61.3 ; $\mathrm{p}<0.0001$ ) among women vs men, indicating lower HRQoL (Table 2).

\section{Impact of HF on the Work Productivity of Patients}

As shown in Table 1, majority of patients were retired $(68.9 \%)$ and $17.7 \%(\mathrm{n}=141)$ were working, including $12.7 \%$ who were working full-time (men: $16.0 \%$; women: $6.7 \%$ ). Results show that HF impacted the productivity of the patients among the working population. Based on responses to the WPAI questionnaire (Table 3), patients reported that $27.4 \%$ of their time at work was impaired owing to HF in the past 7 days; they missed, on average, $9.6 \%$ of work time; and they experienced $29.1 \%$ of overall work impairment due to HF. No significant differences were observed in the WPAI scores by gender. Among all patients, regardless of their working status ( $\mathrm{N}=725$ ), $43.2 \%$ of activity impairment due to $\mathrm{HF}$ 
Table I Patient Demographics and Baseline Clinical Characteristics

\begin{tabular}{|c|c|c|c|c|}
\hline & Overall $(\mathrm{N}=804)$ & Men $(n=5 \mid 7)$ & Women $(n=287)$ & P-value \\
\hline Age (years), mean (SD) & $68.62(11.52)$ & $67.77(11.22)$ & $70.15(11.9)$ & 0.0022 \\
\hline Body mass index $\left(\mathrm{kg} / \mathrm{m}^{2}\right)$, mean (SD) & $27.79(4.49)$ & $27.91(4)$ & $27.57(5.27)$ & 0.025 \\
\hline Ethnicity, n (\%) & $N=804$ & $N=517$ & $N=287$ & 0.7959 \\
\hline White/Caucasian & $760(94.53)$ & $493(95.36)$ & $267(93.03)$ & \\
\hline Asian-Indian subcontinent & $3(0.37)$ & $2(0.39)$ & I $(0.35)$ & \\
\hline Asian - other & $2(0.25)$ & I (0.19) & I $(0.35)$ & \\
\hline Chinese & $\mathrm{I}(0.12)$ & I (0.19) & $0(0.00)$ & \\
\hline Hispanic/Latino & $10(1.24)$ & $6(1.16)$ & $4(1.39)$ & \\
\hline Middle Eastern & $15(1.87)$ & $8(1.55)$ & $7(2.44)$ & \\
\hline Mixed race & $3(0.37)$ & I (0.19) & $2(0.70)$ & \\
\hline Afro-Caribbean (EU) & $10(1.24)$ & $5(0.97)$ & $5(1.74)$ & \\
\hline Smoking status, n (\%) & $N=794$ & $N=512$ & $\mathrm{~N}=282$ & $<0.0001$ \\
\hline Current smoker & $92(11.59)$ & 7I (I3.87) & $21(7.45)$ & \\
\hline Ex-smoker & $35 I(44.2 I)$ & $278(54.30)$ & $73(25.89)$ & \\
\hline Never smoked & $35 I(44.2 I)$ & $163(31.84)$ & $188(66.67)$ & \\
\hline Alcohol consumption, $\mathbf{n}(\%)$ & $N=774$ & $n=503$ & $n=271$ & $<0.0001$ \\
\hline Drinks alcohol currently & $173(22.35)$ & $140(27.83)$ & $33(12.18)$ & \\
\hline Used to drink earlier & $316(40.83)$ & $230(45.73)$ & $86(31.73)$ & \\
\hline Never drunk alcohol & $285(36.82)$ & $133(26.44)$ & $152(56.09)$ & \\
\hline Living status n (\%) & $N=804$ & $N=517$ & $N=287$ & $<0.0001$ \\
\hline Alone & $177(22.01)$ & $85(16.44)$ & $92(32.06)$ & \\
\hline With spouse/partner & 569 (70.77) & 407 (78.72) & $162(56.45)$ & \\
\hline With other family & $41(5.10)$ & $15(2.90)$ & $26(9.06)$ & \\
\hline With friends & $4(0.50)$ & $3(0.58)$ & $\mathrm{I}(0.35)$ & \\
\hline Sheltered home & $6(0.75)$ & $3(0.58)$ & $3(1.05)$ & \\
\hline Nursing home & $4(0.50)$ & $3(0.58)$ & I $(0.35)$ & \\
\hline Other & $3(0.37)$ & I (0.19) & $2(0.70)$ & \\
\hline Time since HF diagnosis (years), mean (SD) & $3.49(4.28)(\mathrm{N}=717)$ & $3.57(4.29)(n=460)$ & $3.36(4.27)(n=257)$ & 0.2604 \\
\hline Current LVEF of patients, mean (SD) & $44.7 \%(9.8 \%)$ & $43.6 \%(9.7 \%)$ & $46.8 \%(9.8 \%)$ & $<0.0001$ \\
\hline NYHA functional class ${ }^{\#}, \mathrm{n}(\%)$ & $N=804$ & $N=517$ & $N=287$ & 0.6968 \\
\hline I & $117(14.55)$ & $70(13.54)$ & $47(16.38)$ & \\
\hline ॥ & $502(62.44)$ & $328(63.44)$ & $174(60.63)$ & \\
\hline III & $165(20.52)$ & $107(20.70)$ & $58(20.21)$ & \\
\hline IV & $20(2.49)$ & $12(2.32)$ & $8(2.79)$ & \\
\hline Employment status, $\mathbf{n}(\%)$ & $N=795$ & $n=512$ & $n=283$ & $<0.0001$ \\
\hline Retired & $548(68.93)$ & $363(70.90)$ & $185(65.37)$ & \\
\hline Working full-time & $101(12.70)$ & $82(16.02)$ & $19(6.7 I)$ & \\
\hline Homemaker & $50(6.29)$ & I $(0.20)$ & $49(17.31)$ & \\
\hline Working part-time & $40(5.03)$ & $26(5.08)$ & $14(4.95)$ & \\
\hline On long-term sick leave & $27(3.40)$ & $22(4.30)$ & $5(1.77)$ & \\
\hline Unemployed & $27(3.40)$ & $18(3.52)$ & $9(3.18)$ & \\
\hline Student & $2(0.25)$ & $0(0.00)$ & $2(0.7 \mathrm{I})$ & \\
\hline Common comorbidities, $\mathbf{n}(\%)$ & $N=804$ & $N=517$ & $\mathrm{~N}=287$ & \\
\hline Hypertension & $443(55.10)$ & $282(54.55)$ & $161(56.10)$ & 0.7115 \\
\hline Hyperlipidemia & $291(36.19)$ & $193(37.33)$ & $98(34.15)$ & 0.3997 \\
\hline
\end{tabular}

(Continued) 
Table I (Continued).

\begin{tabular}{|c|c|c|c|c|}
\hline & Overall $(N=804)$ & Men (n=5 I7) & Women $(n=287)$ & P-value \\
\hline Atrial fibrillation & 161 (20.02) & $98(18.96)$ & $63(21.95)$ & 0.313 \\
\hline Anxiety & $154(19.15)$ & $95(18.38)$ & $59(20.56)$ & 0.4556 \\
\hline Diabetes without chronic complications & $136(16.92)$ & $90(\mid 7.4 I)$ & $46(16.03)$ & 0.6946 \\
\hline Coronary heart/artery disease & $126(15.67)$ & $92(17.79)$ & $34(11.85)$ & 0.0262 \\
\hline Depression & $124(15.42)$ & $66(12.77)$ & $58(20.21)$ & 0.0059 \\
\hline Treatments, n (\%) & $N=804$ & $N=517$ & $N=287$ & \\
\hline$\beta$-blockers & $582(72.39)$ & $385(74.47)$ & $197(68.64)$ & 0.0839 \\
\hline Diuretics & $531(66.04)$ & $333(64.4 I)$ & $198(68.99)$ & 0.2136 \\
\hline ACE inhibitors & $457(56.84)$ & $294(56.87)$ & $163(56.79)$ & I \\
\hline Cholesterol medications & $354(44.03)$ & $24 I(46.62)$ & $113(39.37)$ & 0.0538 \\
\hline Antiplatelets & $237(29.48)$ & $170(32.88)$ & $67(23.34)$ & 0.0047 \\
\hline Mineral receptor antagonists & $193(24.00)$ & $127(24.56)$ & $66(23.00)$ & 0.6668 \\
\hline Angiotensin receptor blockers & $187(23.26)$ & $122(23.60)$ & $65(22.65)$ & 0.7942 \\
\hline Anticoagulants & $163(20.27)$ & $101(19.54)$ & $62(21.60)$ & 0.5218 \\
\hline Calcium channel blockers & 143 (17.79) & $88(17.02)$ & $55(19.16)$ & 0.4432 \\
\hline Sacubitril/valsartan & $98(12.19)$ & $67(12.96)$ & $31(10.80)$ & 0.4311 \\
\hline No HF treatment & $28(3.48)$ & $17(3.29)$ & II (3.83) & 0.6916 \\
\hline
\end{tabular}

Notes: ${ }^{*}$ NYHA class is based on patient record forms data but only for the patients who completed a patient self-completion questionnaire. The $p$ values in bold indicate statistically significant difference $(p<0.05)$.

Abbreviations: ACE, angiotensin-converting enzyme; EU, European Union; HF, heart failure; LVEF, left ventricular ejection fraction; NYHA, New York Heart Association; $\mathrm{SD}$, standard deviation.

was reported, with a significantly greater activity impairment reported in women vs men $(46.4 \%$ vs $41.4 \%$; $\mathrm{p}=0.01)($ Table 3$)$.

\section{Clinical Burden of HF}

Patients reported visiting a doctor owing to $\mathrm{HF} 4.7$ times on an average during the last 12 months, with a similar number of visits between women and men (Table 4). Based on data from patient record forms, $30.7 \%$ of patients were hospitalized at least once for any cause and $23.4 \%$ were hospitalized due to $\mathrm{HF}$. A higher proportion of women compared with men were hospitalized at least once for any cause as well as owing to HF. The mean (SD) number of hospitalizations for any cause $(0.54$ [0.99] vs 0.46 [0.97]) and those owing to $\mathrm{HF}(0.38[0.85]$ vs 0.32 [0.83]) were also higher among women vs men. Worsening or uncontrolled HF symptoms were the most common reason for hospitalizations for HF (79\% of all HF-related hospitalizations); this occurred more frequently in women compared with men ( $82 \%$ vs $78 \%)$. On average, patients spent 5.3 nights in the hospital per visit in the last 12 months, with no significant difference by gender (Table 4).

\section{Patient Treatments and Compliance}

Information on treatments used at the time of data collection showed that $\beta$-blockers, diuretics, and angiotensin-converting enzyme (ACE) inhibitors were the most common therapies among these patients, with use of $\beta$-blockers being numerically higher among men versus women (74.5\% vs $68.6 \%$ ) whereas the use of diuretics was numerically greater among women (64.4\% vs $69.0 \%)$. Of note, the use of antiplatelet therapies was significantly higher among men compared with women $(32.9 \%$ vs $23.3 \%$; $\mathrm{p}=0.0047)$. The use of other treatments appeared to be similar among both sexes (Table 1).

The data on compliance to treatments indicated no significant differences between men and women. Physicianreported data revealed that $77.5 \%$ of overall patients were fully compliant (who took $>80 \%$ of prescribed dose) to their HF treatments (men, 76.6\%; women, 79.0\%). Patientreported data showed that a large majority of patients stated that they always took their HF medications exactly as advised by the doctor $(78.7 \%)$, or they never forgot to take their HF medicine (71.0\%; Table 5).

\section{Discussion}

The results of this cross-sectional study characterizing the burden of HF patients from five major countries in Europe 


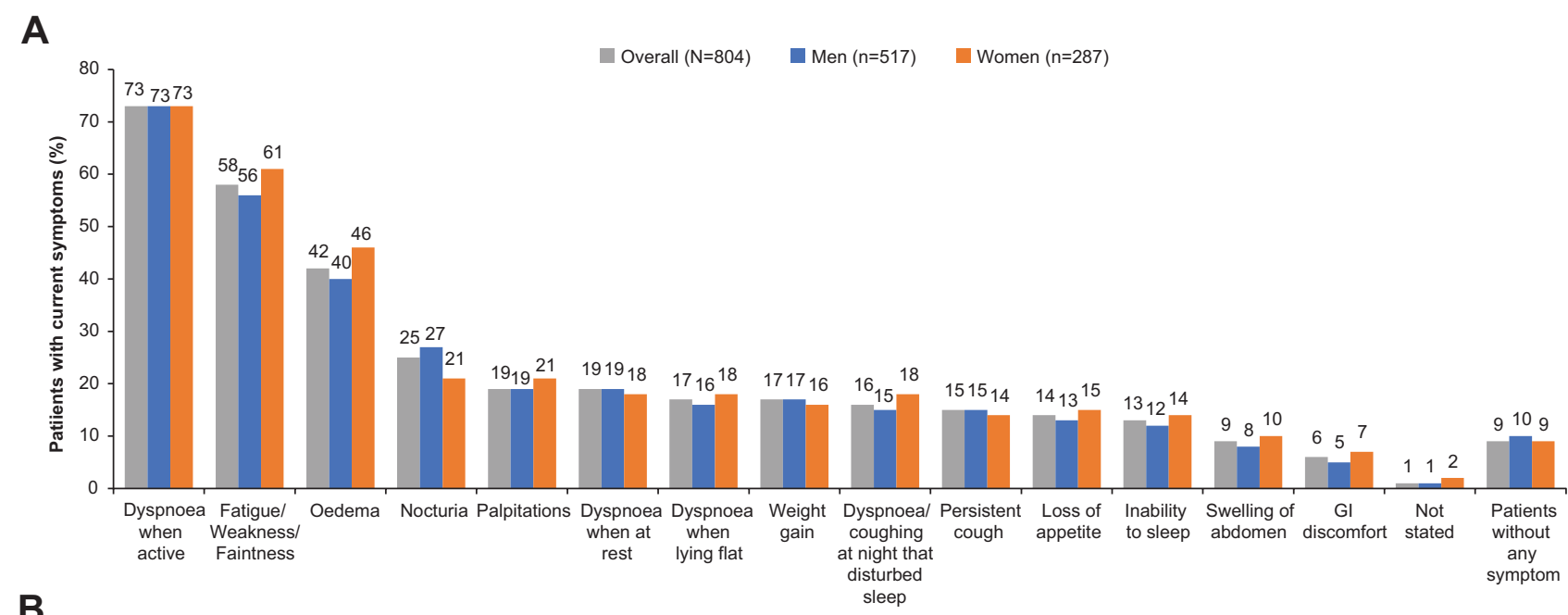

B

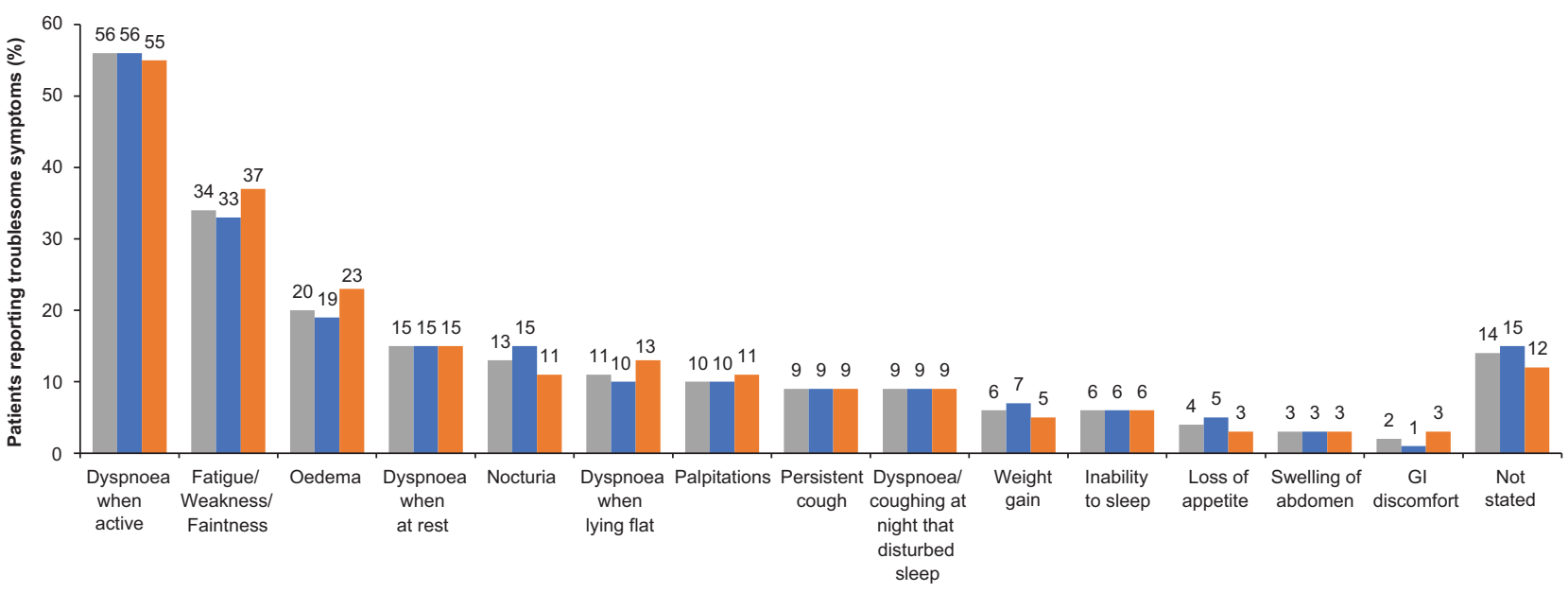

Figure I Patients with heart failure who reported: (A) Current symptoms. (B) Most troublesome symptoms. Abbreviation: $\mathrm{Gl}$, gastrointestinal.

show that patients with HF and LVEF $\leq 60 \%$ have impaired HRQoL. The HRQoL of women with HF was significantly lower compared with HRQoL of men with $\mathrm{HF}$, including the aspects of physical and emotional health such as feelings of low mood/depression and anxiety. The activity impairment due to HF was significantly more in women vs men. Hospitalizations for any cause as well as due to HF were also higher among women compared with men. The overall findings indicate a higher burden of HF in women vs men.

Patients surveyed in this study were retired elderly patients with a median age of 70 years and a higher proportion were male. The baseline characteristics and comorbidities were consistent with those of other surveys/cross-sectional studies on chronic HF patients from Europe, as well as with those of other DSPTM HF studies. $^{31-35}$ The occurrence of common and most troublesome symptoms was also in line with that in previous studies. ${ }^{36}$ The five most troublesome symptoms reported by the patients correlated with the most frequently reported symptoms, with the exception of shortness of breath when at rest, which frequently bothered patients despite not being the most common symptom. This is similar to the findings by Jackson et al in another DSPTM HF study. ${ }^{33}$

The burden of disease seemed to be significantly different between the two genders, despite both groups reporting similar levels of disruption in their everyday life. More than half of the HF patients in this study had depression (54\%) and anxiety (55\%), with a higher occurrence observed among women vs men. Previous research suggests that depressive symptoms and anxiety are common in chronic HF patients. ${ }^{37,38}$ A meta-analysis of 36 studies showed that the mean prevalence rate of clinically 
A

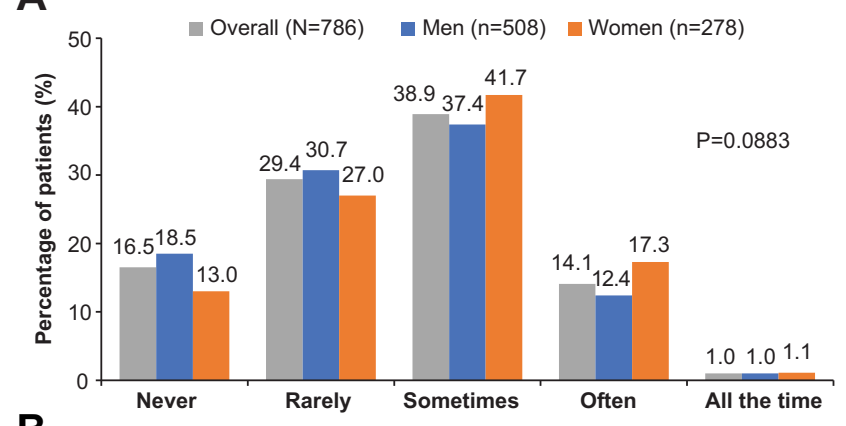

\section{B}

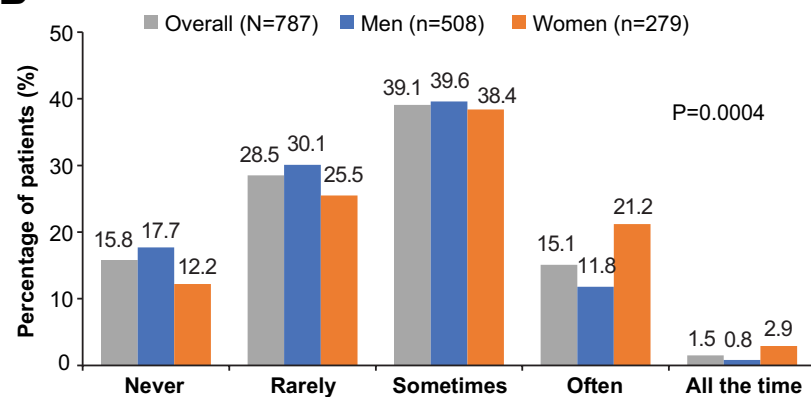

Figure 2 Patients with heart failure who reported: (A) Feelings of low mood/ depression. (B) Feelings of anxiety.

significant depression among chronic $\mathrm{HF}$ patients was $21.5 \%{ }^{39}$ and was reported to vary with the type of study technique (questionnaires: $33.6 \%$; diagnostic interview: $19.3 \%$ ) and NYHA HF class (I: $11 \%$; II: $20 \%$; III: $38 \%$; and IV: $42 \%) .{ }^{39}$ Given that most patients in the present study belonged to NYHA classes II-IV, the depressive symptoms in more than half of the patients appeared to be consistent with those in published literature. ${ }^{39}$ Although the proportion of men and women in the less severe HF stages (ie, NYHA I and II) was equal, HRQoL was poorer among women vs men. The higher reporting of depression and anxiety among women compared with that in men may also be related to their baseline characteristics, since women were older and more likely to live alone. Previous research has shown that HF patients living alone are more prone to distress and social isolation leading to poor health outcomes. ${ }^{40}$ Moreover, the studies characterizing depression and anxiety across genders in HF patients have consistently shown a higher occurrence of depression and anxiety among women vs men. ${ }^{9,41}$ Depressive symptoms have been shown to be a strong predictor of worsening health in HF patients ${ }^{42}$ and are associated with worse physical functioning, worse HF symptoms, increased hospitalizations, and increased mortality. ${ }^{37,38}$

The HRQoL in the present study was assessed using MLHFQ, which is a widely used disease-specific HRQoL questionnaire validated for HF patients. ${ }^{24,43}$ We observed a mean overall MLHFQ score of 35.7, consistent with the overall (mean) MLHFQ scores reported in several studies from Europe ${ }^{44-47}$ ranging from $29.0^{47}$ to $40.9 .{ }^{46}$ Results suggested a significantly higher score (ie, poorer HRQoL) for women vs men (37.8 vs 34.5). The HRQoL of women with HF is consistently poorer vs men with $\mathrm{HF}$, as reported by a meta-analysis of 15 studies with mean total MLHFQ scores of 45.6 and 40.7 , respectively. ${ }^{48}$ This trend was also found to be similar to that in clinical studies such as the PARAGON-HF trial in HF patients with an LVEF of

Table 2 MLHFQ and EQ-5D Scores for HRQoL of Patients with HF

\begin{tabular}{|c|c|c|c|c|}
\hline Scale Score & Overall $(\mathrm{N}=804)$ & Men $(n=5 \mid 7)$ & Women $(n=287)$ & P-value \\
\hline \multicolumn{5}{|l|}{ MLHFQ scale } \\
\hline Overall score & $N=624$ & $n=40 I$ & $n=223$ & \\
\hline Mean (SD) & $35.8(21.4)$ & $34.6(21.6)$ & $37.9(20.9)$ & $0.048 I$ \\
\hline Physical domain score & $N=728$ & $n=46 I$ & $n=267$ & \\
\hline Mean (SD) & $17.4(9.8)$ & $16.6(9.9)$ & $18.6(9.5)$ & $0.004 I$ \\
\hline Emotional domain score & $N=753$ & $n=486$ & $n=267$ & \\
\hline Mean (SD) & $8.4(6.2)$ & $7.9(6.0)$ & $9.4(6.4)$ & 0.0021 \\
\hline \multicolumn{5}{|l|}{ EQ-5D-5L scale } \\
\hline Utility score & $N=783$ & $n=505$ & $\mathrm{n}=278$ & \\
\hline Mean (SD) & $0.73(0.25)$ & $0.75(0.23)$ & $0.69(0.28)$ & 0.0046 \\
\hline VAS score & $N=783$ & $\mathrm{n}=502$ & $n=281$ & \\
\hline Mean (SD) & $59.2(19.1)$ & $61.3(18.4)$ & $55.4(19.7)$ & $<0.0001$ \\
\hline
\end{tabular}

Notes: MLHFQ: higher score indicates a worse quality of life. Range for overall score is 0-105; physical, 0-40; emotional, 0-25. EQ5D-5L VAS: Lower score indicates poorer HRQoL. Range for VAS score is $0-100$. The $p$ values in bold indicate statistically significant difference $(p<0.05)$.

Abbreviations: EQ5D, European Quality of Life Scale 5-dimension; HF, heart failure; HRQoL; health-related quality of life; MLHFQ: The Minnesota Living With Heart Failure Questionnaire; SD, standard deviation; VAS; visual analog scale. 
Table 3 Impact of HF on Activity Impairment and Work Productivity Among Patients with HF

\begin{tabular}{|c|c|c|c|c|}
\hline WPAI Scale & Overall $(\mathrm{N}=804)$ & Men $(n=5 \mid 7)$ & Women $(n=287)$ & P-value \\
\hline $\begin{array}{l}\text { Percentage activity impairment due to HF } \\
\text { Mean (SD) }\end{array}$ & $\begin{array}{c}N=725 \\
43.2(25.0)\end{array}$ & $\begin{array}{c}n=464 \\
4 I .4(25.0)\end{array}$ & $\begin{array}{c}n=261 \\
46.4(24.8)\end{array}$ & 0.01 \\
\hline $\begin{array}{l}\text { Percentage impairment while working due to HF } \\
\text { Mean (SD) }\end{array}$ & $\begin{array}{c}\mathrm{N}=109 \\
27.4(23.0)\end{array}$ & $\begin{array}{c}n=83 \\
28.2(23.0)\end{array}$ & $\begin{array}{c}n=26 \\
25.0(23.0)\end{array}$ & 0.5384 \\
\hline $\begin{array}{l}\text { Percentage work time missed due to HF } \\
\text { Mean (SD) }\end{array}$ & $\begin{array}{l}N=108 \\
9.6(26.4)\end{array}$ & $\begin{array}{c}n=83 \\
10.7(27.7)\end{array}$ & $\begin{array}{c}n=25 \\
5.6(21.2)\end{array}$ & 0.3954 \\
\hline $\begin{array}{l}\text { Percentage overall work impairment due to HF } \\
\text { Mean (SD) }\end{array}$ & $\begin{array}{c}N=101 \\
29.1(24.5)\end{array}$ & $\begin{array}{c}n=77 \\
29.9(24.7)\end{array}$ & $\begin{array}{c}n=24 \\
26.6(24.2)\end{array}$ & 0.5684 \\
\hline
\end{tabular}

Note: The $p$ values in bold indicate statistically significant difference $(p<0.05)$.

Abbreviations: HF, heart failure; SD, standard deviation; WPAI, Work Productivity and Activity Impairment scale.

$\geq 45 \%{ }^{49}$ Similar results were also seen for EQ-5D scores, with a significantly lower $(\mathrm{p}=0.0046)$ utility score among women vs men (0.69 vs 0.75$)$, which is also in line with previous findings. ${ }^{49,50}$ As noted, HF impacted work productivity among working patients. Patients reported $43 \%$ of activity impairment due to HF, which was found to be consistent with a previous study. ${ }^{33}$

A prior analysis from this study reporting symptoms and HRQoL of patients stratified into those with LVEF $<40 \%$ and $\mathrm{LVEF} \geq 40-60 \%$ revealed that patient-reported symptoms of HF and baseline comorbidities were higher among patients with LVEF $<40 \%$ compared to those with LVEF $\geq 40 \%-60 \%$. Also, the patients with LVEF $<40 \%$ reported statistically significantly worse HRQoL compared to those with LVEF $\geq 40 \%-60 \%{ }^{51}$ These findings were consistent with literature reporting lower HRQoL in patients with LVEF $<40 \%$ compared to those with LVEF $40-49 \%$ and $>50 \%{ }^{52}$ The analysis from PARAGON-HF trial in patients with HF with median LVEF $57 \%$ showed that HRQoL assessed using Kansas City Cardiomyopathy Questionnaire was largely worse in women than men, and was similar in HFpEF and HFrEF after adjusting for potential confounding factors. ${ }^{49}$ Our analysis was limited to stratification based on LVEF status of the patients further subgroups based on sex within each LVEF category were not evaluated, and could be avenues for further research.

Patients in the present study had approximately five visits to a doctor owing to $\mathrm{HF}$ in the year prior to the survey. Approximately one-quarter of the patients were hospitalized in the last year owing to HF, and the mean number of HF hospitalizations was 0.35 . These findings appeared to be consistent with those of our previous $\mathrm{HF}$
DSPTM studies, which reported hospitalizations owing to $\mathrm{HF}$ in $30 \%$ of the patients with a mean number of $\mathrm{HF}$ hospitalizations of $0.40 .^{53}$ Worsening or uncontrolled symptoms of HF was the most common reason for $\mathrm{HF}$ hospitalizations. This clinical burden was also higher among women compared with that in men, although the differences were not statistically significant. A recently published retrospective, population-based study analyzing 20 -year trends showed that although the number of hospitalizations owing to HF in 2012-2015 was similar across both genders (ie, 22 per 100 person-years), the annual increase in HF hospitalizations was $2.6 \%$ in women compared with stable rates in men $(0.6 \%){ }^{54}$ This means that hospitalizations owing to HF are likely to increase among women, which will ultimately lead to a greater clinical burden among them. Although the economic burden was not assessed in this study, the HF hospitalizations, visits to the doctor, and work productivity loss due to HF reported here pose a substantial financial burden on the healthcare system and society. Costs of hospital visits have been reported to comprise a major portion of the HF-related healthcare costs. ${ }^{8}$ Repeat HF hospitalizations account for $1-2 \%$ of the total direct healthcare expenditure of developed countries. ${ }^{8,55}$

The 2016 ESC guidelines recommend the use of ACE inhibitors, angiotensin receptor blockers, $\beta$-blockers and mineralocorticoid-receptor antagonists in patients with HFrEF. ${ }^{1}$ The use of sacubitril/valsartan to replace ACE inhibitors in ambulatory HFrEF patients who remain symptomatic despite optimal therapy is also recommended. ${ }^{1}$ These medications can be used in conjunction with diuretics based on patients' symptoms and/ or sign of congestion. ${ }^{1}$ Of note, $\beta$-blockers, diuretics, and 
Table 4 Clinical Burden of HF Based on Patient Record Form Data Completed by Physician

\begin{tabular}{|c|c|c|c|c|}
\hline & $\begin{array}{l}\text { Overall } \\
(\mathrm{N}=804)\end{array}$ & $\begin{array}{c}\text { Men } \\
(n=5 \mid 7)\end{array}$ & $\begin{array}{l}\text { Women } \\
(n=287)\end{array}$ & P-value \\
\hline $\begin{array}{l}\text { Number of times a patient visited a doctor in relation to HF condition in } \\
\text { the last } 12 \text { months* }\end{array}$ & $\mathrm{N}=770$ & $\mathrm{n}=493$ & $\mathrm{n}=277$ & 0.4426 \\
\hline Mean (SD) & $4.7(4.4)$ & $4.6(4.6)$ & $4.9(4.2)$ & \\
\hline Number of hospitalization for any cause in the last 12 months, $n$ (\%) & $N=667$ & $n=419$ & $n=248$ & 0.1512 \\
\hline 0 & $462(69.3)$ & $294(70.2)$ & $168(67.7)$ & \\
\hline I & $137(20.5)$ & $89(21.2)$ & $48(19.4)$ & \\
\hline 2 & $40(6.0)$ & $20(4.8)$ & $20(8.1)$ & \\
\hline 3 & $15(2.3)$ & $7(1.7)$ & $8(3.2)$ & \\
\hline 4 & $8(1.2)$ & $7(1.7)$ & I $(0.4)$ & \\
\hline $5+$ & $5(0.8)$ & $2(0.5)$ & $3(1.2)$ & \\
\hline Hospitalization for any cause in the last 12 months & $N=667$ & $n=419$ & $n=248$ & 0.3484 \\
\hline Mean (SD) & $0.49(0.97)$ & $0.46(0.97)$ & $0.54(0.99)$ & \\
\hline Number of hospitalization due to HF in the last 12 months, $n$ (\%) & $N=667$ & $n=419$ & $n=248$ & 0.6766 \\
\hline 0 & $5 I I(76.6)$ & $324(77.3)$ & $187(75.4)$ & \\
\hline I & $116(17.4)$ & $74(17.7)$ & $42(16.9)$ & \\
\hline 2 & $25(3.8)$ & $14(3.3)$ & II (4.4) & \\
\hline 3 & $6(0.9)$ & $2(0.5)$ & $4(1.6)$ & \\
\hline 4 & $5(0.8)$ & $3(0.7)$ & $2(0.8)$ & \\
\hline $5+$ & $4(0.6)$ & $2(0.5)$ & $2(0.8)$ & \\
\hline Hospitalization due to HF in the last 12 months & $N=667$ & $n=419$ & $n=248$ & 0.3838 \\
\hline Mean (SD) & $0.35(0.84)$ & $0.32(0.83)$ & $0.38(0.85)$ & \\
\hline Hospitalization level data & $N=268$ & $n=166$ & $n=102$ & \\
\hline Reasons for HF related hospitalization in the last 12 months, $n$ (\%) & $N=26 I$ & $n=160$ & $n=101$ & 0.4634 \\
\hline Worsening/uncontrolled HF symptoms & $207(79.3)$ & $124(77.5)$ & $83(82.2)$ & \\
\hline HF treatment side effects & $5(1.9)$ & $2(1.3)$ & $3(3.0)$ & \\
\hline For surgery & $18(6.9)$ & $12(7.5)$ & $6(5.9)$ & \\
\hline Other HF related reason & $31(11.9)$ & $22(13.8)$ & $9(8.9)$ & \\
\hline $\begin{array}{l}\text { Patients admitted through ER for HF related hospitalization in the last I } 2 \\
\text { months, } \mathrm{n}(\%)\end{array}$ & $N=259$ & $n=160$ & $\mathrm{n}=99$ & 0.1918 \\
\hline Yes & $192(74.1)$ & II4 (7I.3) & $78(78.8)$ & \\
\hline No & $67(25.9)$ & 46 (28.7) & $2 \mid(2 \mid .2)$ & \\
\hline $\begin{array}{l}\text { Number of nights spent in hospital for HF related hospitalizations in the } \\
\text { last } 12 \text { months }\end{array}$ & $N=193$ & $\mathrm{n}=118$ & $n=75$ & 0.3474 \\
\hline Mean (SD) & $5.3(4.1)$ & $5.5(4.7)$ & $4.9(2.9)$ & \\
\hline
\end{tabular}

Note: *Data set is patient self-completion questionnaire.

Abbreviations: ER, emergency room; HF, heart failure; SD, standard deviation.

ACE inhibitors were the most commonly used treatments in the present study. There was no significant difference in the use of these treatments by sex. Patients were optimally treated in this study as suggested by the high compliance rates to their HF medications. Previous research has shown that higher medication adherence was associated with reductions in emergency room visits, hospital admissions, length of hospital stay, and all-cause mortality. ${ }^{56}$

The overall evidence suggests that HF has a substantial impact on patients' HRQoL, with women presenting with a poorer HRQoL than men. Women reported more impairment in physical and emotional health and were hospitalized more 
Table 5 Compliance Among Patients with HF for the Treatments They Were Receiving

\begin{tabular}{|c|c|c|c|}
\hline & $\begin{array}{l}\text { Overall } \\
(\mathbf{N}=804)\end{array}$ & $\begin{array}{c}\text { Men* } \\
(n=5 \mid 7)\end{array}$ & $\begin{array}{l}\text { Women* } \\
(\mathrm{n}=\mathbf{2 8 7})\end{array}$ \\
\hline 'In your experience, how compliant is this patient with their heart failure treatment, $\mathrm{n}(\%)$ & $N=750$ & $n=483$ & $n=267$ \\
\hline Poor compliance (takes $<50 \%$ of prescribed dose) & $14(1.87)$ & $8(1.66)$ & $6(2.25)$ \\
\hline Fairly compliant (takes $50-80 \%$ of prescribed dose) & $151(20.13)$ & $104(21.53)$ & $47(17.60)$ \\
\hline Fully compliant (takes $>80 \%$ of prescribed dose) & $581(77.47)$ & $370(76.60)$ & $211(79.03)$ \\
\hline $\begin{array}{l}\text { \#How often do you take your heart failure medicine exactly as advised by your doctor eg in } \\
\text { relation to time and dose?, n (\%) }\end{array}$ & $N=759$ & $\mathrm{n}=489$ & $\mathrm{n}=270$ \\
\hline All the time & $597(78.66)$ & $387(79.14)$ & $210(77.78)$ \\
\hline${ }^{\#}$ How often do you forget to take your heart failure medicine?, n (\%) & $N=753$ & $n=484$ & $n=269$ \\
\hline Never & $535(71.05)$ & $350(72.31)$ & $185(68.77)$ \\
\hline \#If you feel better do you ever stop taking your heart failure medicine?, n (\%) & $N=753$ & $n=484$ & $n=269$ \\
\hline All the time & $10(1.33)$ & $8(1.65)$ & $2(0.74)$ \\
\hline $\begin{array}{l}\text { \#How often do you not get your heart failure medicine because it costs too much money?, } \\
\text { n (\%) }\end{array}$ & $N=75$ I & $n=483$ & $n=268$ \\
\hline Never & $655(87.22)$ & $418(86.54)$ & $237(88.43)$ \\
\hline $\begin{array}{l}\text { \#Do you fail to take your heart failure medicine because you do not like the way you have to } \\
\text { take it, ie, tablet or injection?, n (\%) }\end{array}$ & $N=751$ & $n=483$ & $n=268$ \\
\hline Never & $651(86.68)$ & $4 \mid 4(85.7 I)$ & $237(88.43)$ \\
\hline
\end{tabular}

Notes: *The $\mathrm{p}$ value for the difference between men and women was non-significant. ${ }^{\dagger}$ Physician reported. ${ }^{*}$ Patient reported.

Abbreviation: HF, heart failure.

often despite having a higher mean LVEF than men. These aspects suggest that there are meaningful differences between men and women in HF progression and impact that need to be better understood to optimize patient care. Overall, there is a need for more effective treatments to ensure adequate control of HF symptoms and to reduce the HRQoL burden. The Heart Failure Policy Network in Europe ${ }^{8}$ focusing on improving the prevention, management, and care of $\mathrm{HF}$ recommends that $\mathrm{HF}$ should be a priority policy because (a) prevalence is increasing, (b) awareness is low and symptoms are not recognized by most people, (c) several of the HF cases could be prevented, (d) outcomes are poorer than several common cancers, (e) HF poses a considerable and growing healthcare burden to society, and (f) HF is managed suboptimally and significant disparities exist in management of HF.

This study has certain limitations. The sample may not represent the overall population of HF patients, as only eight consecutive suitable HF patients who consulted the physicians were included. This could have led to the inclusion of patients who consulted more frequently.
Although physician selection involved minimal exclusion criteria, the willingness of physicians to participate in the study and limitations of geographical location could have influenced their selection. Data collected in surveys of this type may be subject to recall bias by physicians and patients. Patient self-completion questionnaires were completed voluntarily; thus, they may reflect a more motivated subpopulation. No adjustments were made for patients' clinical characteristics for comparison between men and women. Therefore, the results reflect the differences observed in patients as seen in practice. Of note, women in the present study were significantly older and more frequently lived alone than men, and this could have impacted their burden of disease. Overall, Adelphi's DSP $^{\mathrm{TM}}$ has a well-established methodology ${ }^{23}$ for conducting cross-sectional survey studies in real-world settings.

\section{Conclusion}

In conclusion, evidence from this real-world study showed that patients with HF with an LVEF of $\leq 60 \%$ have 
a reduced HRQoL and that HF presents substantial disruption to patients' everyday life in Europe. Importantly, this study shows that HF poses a higher burden and is associated with significantly lower HRQoL among women compared with men, including the aspects of physical and emotional health such as low mood/depression and anxiety. The burden of hospitalizations was also higher among women compared with that in men. These sex difference in the burden of disease is consistent with other studies in HF and warrants further investigation to better understand the underlying reasons and support optimal patient care.

\section{Acknowledgments}

Medical writing assistance was provided by Raju Gautam and Lovneet Saini, who are employees of Novartis Healthcare Pvt. Ltd., Hyderabad, India.

\section{Funding}

This study was funded by Novartis Pharma AG, Basel, Switzerland.

\section{Disclosure}

The abstract of this paper was presented at the European Society of Cardiology (ESC) Congress, August 29 September 02, 2020 as a poster presentation with interim findings. The poster's abstract was published in European Journal of Heart Failure, Supplement: HFA Discoveries Abstract. 2020; 22(S1): https://esc365.escardio.org/ Presentation/223187/abstract

A. F. Fonseca, R. Lahoz, C. Proudfoot, S. Corda and R. Studer are employees of Novartis Pharma AG, Basel, Switzerland. E. Loefroth was an employee of Novartis Pharma AG at the time of conduct of this study. J. Jackson and S. Cotton are employees of Adelphi Real World and were contracted by Novartis to conduct this study.

\section{References}

1. Ponikowski P, Voors AA, Anker SD, et al. 2016 ESC Guidelines for the diagnosis and treatment of acute and chronic heart failure: the Task Force for the diagnosis and treatment of acute and chronic heart failure of the European Society of Cardiology (ESC). Developed with the special contribution of the Heart Failure Association (HFA) of the ESC. Eur J Heart Fail. 2016;18:891-975.

2. Milinković I, Giuseppe R, Lopatin Y, Seferović PM. The role of ivabradine and trimetazidine in the new ESC HF guidelines. Cardiac Failure Rev. 2016;2:123.
3. Westenbrink BD, Brugts JJ, McDonagh TA, Filippatos G, Ruschitzka F, Van Laake LW. Heart failure specialization in Europe. Eur J Heart Fail. 2016;18:347-349. doi:10.1002/ejhf.506

4. Khavjou O, Phelps D, Leib A. Projections of Cardiovascular Disease Prevalence and Costs: 2015-2035. Technical report; 2016. Available from: https://healthmetrics.heart.org/wp-content/uploads/2017/10/ Projections-of-Cardiovascular-Disease.pdf. Accessed July 8, 2021.

5. Jeon YH, Kraus SG, Jowsey T, Glasgow NJ. The experience of living with chronic heart failure: a narrative review of qualitative studies. BMC Health Serv Res. 2010;10:77. doi:10.1186/1472-6963-10-77

6. Stewart S, Ekman I, Ekman T, Odén A, Rosengren A. Population impact of heart failure and the most common forms of cancer: a study of 1162309 hospital cases in Sweden (1988 to 2004). CircCardiovase Qual. 2010;3:573-580. doi:10.1161/ CIRCOUTCOMES.110.957571

7. Norberg EB, Boman K, Löfgren B. Activities of daily living for old persons in primary health care with chronic heart failure. Scand $J \quad$ Caring Sci. 2008;22:203-210. doi:10.1111/j.14716712.2007.00514.x

8. Heart Failure Policy Network; 2020. Heart failure policy and practice in Europe. London: HFPN. Available from: https://www.healthpolicy partnership.com/app/uploads/Heart-failure-policy-and-practice-inEurope.pdf.

9. Lesman-Leegte I, Jaarsma T, Coyne JC, Hillege HL, Van Veldhuisen DJ, Sanderman R. Quality of life and depressive symptoms in the elderly: a comparison between patients with heart failure and age-and gender-matched community controls. J Card Fail. 2009;15:17-23. doi:10.1016/j.cardfail.2008.09.006

10. Broström A, Strömberg A, Dahlström U, Fridlund B. Sleep difficulties, daytime sleepiness, and health-related quality of life in patients with chronic heart failure. J Cardiovasc Nurs. 2004;19:234-242. doi:10.1097/00005082-200407000-00003

11. Cowie MR, Anker SD, Cleland JG, et al. Improving care for patients with acute heart failure: before, during and after hospitalization. ESC Heart Fail. 2014;1:110-145.

12. Calvert MJ, Freemantle N, Cleland JG. The impact of chronic heart failure on health-related quality of life data acquired in the baseline phase of the CARE-HF study. Eur J Heart Fail. 2005;7:243-251. doi:10.1016/j.ejheart.2005.01.012

13. Faxén UL, Hage C, Donal E, Daubert JC, Linde C, Lund LH. Patient reported outcome in HFpEF: sex-specific differences in quality of life and association with outcome. Int $J$ Cardiol. 2018;267:128-132. doi:10.1016/j.ijcard.2018.04.102

14. Friedman MM. Gender differences in the health related quality of life of older adults with heart failure. Heart Lung. 2003;32:320-327. doi:10.1016/S0147-9563(03)00098-0

15. Yusuf S, Pfeffer MA, Swedberg K, et al. Effects of candesartan in patients with chronic heart failure and preserved left-ventricular ejection fraction: the CHARM-Preserved Trial. Lancet (London, England). 2003;362(9386):777-781. doi:10.1016/S0140-6736(03) 14285-7

16. Solomon SD, McMurray JJV, Anand IS, et al. AngiotensinNeprilysin Inhibition in Heart Failure with Preserved Ejection Fraction. NEJM. 2019;381:1609-1620. doi:10.1056/ NEJMoa1908655

17. Lam CSP, Voors AA, Piotr P, McMurray JJV, Solomon SD. Time to rename the middle child of heart failure: heart failure with mildly reduced ejection fraction. Eur Heart J. 2020;41:2353-2355. doi:10.1093/eurheartj/ehaa158

18. Triposkiadis F, Butler J, Abboud FM, et al. The continuous heart failure spectrum: moving beyond an ejection fraction classification. Eur Heart J. 2019;40:2155-2163. doi:10.1093/eurheartj/ehz158

19. Novartis Entresto granted expanded indication in chronic heart failure by FDA; February 16, 2021. Available from: https://www.novartis. com/news/media-releases/novartis-entresto-granted-expandedindication-chronic-heart-failure-fda. Accessed June 21, 2021. 
20. McMurray JJ, Packer M, Desai AS, et al. Angiotensin-neprilysin inhibition versus enalapril in heart failure. NEJM. 2014;371:993-1004. doi:10.1056/NEJMoa1409077

21. Babineaux SM, Curtis B, Holbrook T, Milligan G, Piercy J. Evidence for validity of a national physician and patient-reported, cross-sectional survey in China and UK: the Disease Specific Programme. BMJ Open. 2016;6:e010352. doi:10.1136/bmjopen2015-010352

22. Higgins V, Piercy J, Roughley A, et al. Trends in medication use in patients with type 2 diabetes mellitus: a long-term view of real-world treatment between 2000 and 2015. Diabetes Metab Syndr Obes Targets Ther. 2016;9:371-380. doi:10.2147/DMSO.S120101

23. Anderson P, Benford M, Harris N, Karavali M, Piercy J. Real-world physician and patient behaviour across countries: disease-Specific Programmes - a means to understand. Curr Med Res Opin. 2008;24:3063-3072. doi:10.1185/03007990802457040

24. Rector TS, Kubo SH, Cohn JN. Patients' self-assessment of their congestive heart failure. Part 2: content, reliability and validity of a new measure, The Minnesota Living with Heart Failure Questionnaire. Heart Fail. 1987;3:198-209.

25. EuroQol-a new facility for the measurement of health-related quality of life. Health policy (Amsterdam, Netherlands). 16:199-208; 1990.

26. Brooks R. EuroQol: the current state of play. Health Policy (Amsterdam, Netherlands). 1996;37:53-72. doi:10.1016/01688510(96)00822-6

27. Herdman M, Gudex C, Lloyd A, et al. Development and preliminary testing of the new five-level version of EQ-5D (EQ-5D-5L). Qual Life Res. 2011;20:1727-1736. doi:10.1007/s11136-011-9903-x

28. Dyer MT, Goldsmith KA, Sharples LS, Buxton MJ. A review of health utilities using the EQ-5D in studies of cardiovascular disease. Health Qual Life Outcomes. 2010;8:13. doi:10.1186/1477-7525-8-13

29. National Institute for Health and Care Excellence (NICE). Position statement on use of the EQ-5D-5L valuation set for England; Updated October 2019. Available from: https://www.nice.org.uk/ about/what-we-do/our-programmes/nice-guidance/technologyappraisal-guidance/eq-5d-51. Accessed September 15, 2020.

30. Reilly MC, Zbrozek AS, Dukes EM. The validity and reproducibility of a work productivity and activity impairment instrument. PharmacoEconomics. 1993;4:353-365. doi:10.2165/00019053199304050-00006

31. Brugts JJ, Linssen GCM, Hoes AW, Brunner-la Rocca HP. Realworld heart failure management in 10,910 patients with chronic heart failure in the Netherlands: design and rationale of the Chronic Heart failure ESC guideline-based Cardiology practice Quality project (CHECK-HF) registry. Neth Heart J. 2018;26:272-279. doi:10.1007/s12471-018-1103-7

32. van Deursen VM, Urso R, Laroche $\mathrm{C}$, et al. Co-morbidities in patients with heart failure: an analysis of the European Heart Failure Pilot Survey. Eur J Heart Fail. 2014;16:103-111. doi:10.1002/ejhf.30

33. Jackson JD, Cotton SE, Bruce Wirta S, et al. Burden of heart failure on patients from China: results from a cross-sectional survey. Drug Des Devel Ther. 2018;12:1659-1668. doi:10.2147/DDDT.S148949

34. Wirta SB, Balas B, Proenca CC. et al. Perceptions of heart failure symptoms, disease severity, treatment decision-making, and side effects by patients and cardiologists: a multinational survey in a cardiology setting. Ther Clin Risk Manag;2018. 2265-2272. doi: 10.2147/TCRM.S183200

35. Jackson JD, Cotton SE, Bruce Wirta S, et al. Care pathways and treatment patterns for patients with heart failure in China: results from a cross-sectional survey. Drug Des Devel Ther. 2018;12:2311-2321. doi:10.2147/DDDT.S166277

36. Wilson J, McMillan S. Symptoms Experienced by Heart Failure Patients in Hospice Care. J Hosp Palliat Nurs. 2013;15:13-21. doi:10.1097/NJH.0b013e31827ba343
37. Celano CM, Villegas AC, Albanese AM, Gaggin HK, Huffman JC. Depression and Anxiety in Heart Failure: a Review. Harv Rev Psychiatry. 2018;26:175-184. doi:10.1097/HRP.0000000000000162

38. Liguori I, Russo G, Curcio F, et al. Depression and chronic heart failure in the elderly: an intriguing relationship. $J$ Geriatr Cardiol. 2018;15:451-459.

39. Rutledge T, Reis VA, Linke SE, Greenberg BH, Mills PJ. Depression in heart failure a meta-analytic review of prevalence, intervention effects, and associations with clinical outcomes. J Am Coll Cardiol. 2006;48:1527-1537. doi:10.1016/j.jacc.2006.06.055

40. Polikandrioti M, Panoutsopoulos G, Tsami A, et al. Assessment of quality of life and anxiety in heart failure outpatients. Arch Med Sci Atheroscler Dis. 2019;4:e38-e46. doi:10.5114/amsad.2019.84444

41. Lesman-Leegte I, Jaarsma T, Sanderman R, Linssen G, van Veldhuisen DJ. Depressive symptoms are prominent among elderly hospitalised heart failure patients. Eur J Heart Fail. 2006;8:634-640. doi:10.1016/j.ejheart.2005.11.010

42. Rumsfeld JS, Havranek E, Masoudi FA, et al. Depressive symptoms are the strongest predictors of short-term declines in health status in patients with heart failure. J Am Coll Cardiol. 2003;42:1811-1817. doi:10.1016/j.jacc.2003.07.013

43. Bilbao A, Escobar A, García-Perez L, Navarro G, Quirós R. The Minnesota living with heart failure questionnaire: comparison of different factor structures. Health Qual Life Outcomes. 2016;14:23. doi:10.1186/s12955-016-0425-7

44. Årestedt K, Saveman BI, Johansson P, Blomqvist K. Social support and its association with health-related quality of life among older patients with chronic heart failure. Eur $J$ Cardiovasc Nurs. 2013;12:69-77. doi:10.1177/1474515111432997

45. de Rivas B, Permanyer-Miralda G, Brotons C, Aznar J, Sobreviela E. Health-related quality of life in unselected outpatients with heart failure across Spain in two different health care levels. Magnitude and determinants of impairment: the INCA study. Qual Life Res. 2008;17:1229-1238. doi:10.1007/s11136008-9397-3

46. Gallagher AM, Lucas R, Cowie MR. Assessing health-related quality of life in heart failure patients attending an outpatient clinic: a pragmatic approach. ESC Heart Fail. 2019;6:3-9. doi:10.1002/ ehf2.12363

47. Lupón J, Gastelurrutia P, de Antonio M, et al. Quality of life monitoring in ambulatory heart failure patients: temporal changes and prognostic value. Eur J Heart Fail. 2013;15:103-109. doi:10.1093/ eurjhf/hfs 133

48. Moradi M, Daneshi F, Behzadmehr R, Rafiemanesh H, Bouya S, Raeisi M. Quality of life of chronic heart failure patients: a systematic review and meta-analysis. Heart Fail Rev. 2019.

49. Chandra A, Vaduganathan M, Lewis EF, et al. Health-Related Quality of Life in Heart Failure With Preserved Ejection Fraction: the PARAGON-HF Trial. JACC Heart Fail. 2019;7:862-874. doi:10.1016/j.jchf.2019.05.015

50. Comín-Colet J, Anguita M, Formiga F, et al. Health-related Quality of Life of Patients With Chronic Systolic Heart Failure in Spain: results of the VIDA-IC Study. Rev Esp Cardiol (Engl Ed). 2016;69:256-271. doi:10.1016/j.recesp.2015.07.034

51. Proudfoot C, Fonseca AF, Lahoz R, et al. Patients with heart failure and a LVEF less than $40 \%$ present an overall lower health related quality of life than those with LVEF between $40 \%$ and $60 \%$ : a multinational real-world survey in EU. Eur Heart J. 2020;41 (Supplement_2). doi:10.1093/ehjci/ehaa946.0974

52. Chen X, Xin Y, Hu W, et al. Quality of life and outcomes in heart failure patients with ejection fraction in different ranges. PLoS One. 2019;14(6). doi:10.1371/journal.pone.0218983

53. Karpf E, Jackson J, Cotton S, et al. Assessing the Burden of Chronic Heart Failure on Patients in Colombia. Value Health. 2017;20:A623. doi:10.1016/j.jval.2017.08.1362 
54. Lawson CA, Zaccardi F, Squire I, et al. 20-year trends in cause-specific heart failure outcomes by sex, socioeconomic status, and place of diagnosis: a population-based study. Lancet Public Health. 2019;4:e406-e20. doi:10.1016/S2468-2667(19)30108-2

55. Guha K, McDonagh T. Heart failure epidemiology: european perspective. Curr Cardiol Rev. 2013;9:123-127. doi:10.2174/ 1573403X11309020005
56. Hood SR, Giazzon AJ, Seamon G, et al. Association between medication adherence and the outcomes of heart failure. Pharmacotherapy. 2018;38:539-545. doi:10.1002/phar.2107

\section{Publish your work in this journal}

Patient Preference and Adherence is an international, peer-reviewed, open access journal that focusing on the growing importance of patient preference and adherence throughout the therapeutic continuum. Patient satisfaction, acceptability, quality of life, compliance, persistence and their role in developing new therapeutic modalities and compounds to optimize clinical outcomes for existing disease states are major areas of interest for the journal. This journal has been accepted for indexing on PubMed Central. The manuscript management system is completely online and includes a very quick and fair peer-review system, which is all easy to use. Visit http:// www.dovepress.com/testimonials.php to read real quotes from published authors. 